\title{
Risk considerations and Southland farmers
}

\section{S.F.PITTAWAY, D.L.NEWMAN, G.A.ANDERSON and L.S.SAUNDERS Lincoln University. Canterbury}

\begin{abstract}
Results from a recent survey suggest that Southland farmers perceive their farm businesses as being risky, and that this risk has increased significantly over the past decade. More importantly, they perceive that their ability to control these risk factors is limited. It may be argued that a number of potential risk amelioration strategies will not be considered by the majority of farmers as these strategies conflict with some important non-economic farming goals. As a result, any policy initiative which is designed to reduce or limit the risks faced by farmers should be based on a sound understanding of the likely reactions of those farmers.
\end{abstract}

Keywords agricultural risk, risk, risk perceptions, Southland farmers, agricultural policy

\section{Introduction}

The New Zealand agricultural industry has experienced significant structural changes since the election of the Labour Government in 1984. Prior to this, through the provision of such supports as concessionary development finance and suspensory loans, and a number of Producer Board income smoothing schemes, farmers were encouraged to limit the mix of enterprises used in the farming system. With such a high level of support available to farmers, attempts toreduce their overall risk via enterprise diversification were not regarded as being very important.

Since 1984. Government policy initiatives have attempted to shift the responsibility for risk amelioration away from central Government. and onto the individual farmer. Responsibility for adverse events such as cyclones and droughts will not in future be accepted by central Government to the extent that they were in the past. This change in Government policy has largely been motivated in an attempt to avoid the fiscal costs such policies have imposedon taxpayers. Some evidence that the advantages of public assistance becomes imputed into the value of the farm asset may have also contributed to the change in official attitude.

Thus, Government policy since 1984 has encouraged farmers to become more self reliant, to be more aware of the potential risks which they face, and to take more responsibility for dealing with that risk. These changes resulted in two distinct pressures for farmers.

First, the farmer has been encouraged to respond to the increase in business risk by changing and enlarging the mix of enterprises used in the farming system. Commodity prices are no longer supported or guaranteed, and enterprise returns have become directly exposed to variables such as world price levels and a floating exchange rate. Diversification by sheep and cropping farmers has been largely into relatively established assets such as dairying, and to a lesser extent into "new" enterprises such as deer and new arable crops.

Second, the farmer was forced to accept increased financial risk as concessionary finance was no longer available. As debt servicing commitments increased, so too did the volatility of farm incomes and with them, the risk of default.

And yet it appears that little was known about New Zealand farmers' risk perceptions. Policies and programmes that would inevitably impact considerably on the farm business environment were being considered by Government without any empirical evidence to suggest the likely response of farmers to such initiatives.

The study on which this paper is based was completed for the Rural Policy Unit of the Ministry of Agriculture and Fisheries in 1991, and was intended, in part, to identify firstly the perceived sources of risk, and secondly the likely reactions to those risks.

Three different geographical areas were selected for the survey, reflecting the regional and farming systems differences in New Zealand. Canterbury represented mixed cropping farmers, Waikato represented dairying and Southland was chosen because of its nature as a distinct geographical area with relatively standard livestock farming systems.

\section{Relevant theory}

The literature on the subject of farming risk is both diverse and substantial. "Risk" is commonly partitioned into two separate components; business risk and financial risk. Business risk is usually represented by the coefficient of variation of net operating income before the deduction of financial expenses, while financial risk is defined as the additional variability of net cash flows 
that results from debt financing. For the purposes of this paper, the above definitions will be used.

Also of interest is the concept of risk balancing, as advanced by Gabriel \&Baker (1980). They suggest that policies which are promulgated to reduce either business or financial risk will be countered by an equal but opposite reaction by the farmer. until the total risk faced by the individual again reaches some equilibrium risk level. That level is dependent on that individual's preference for risk.

This hypothesised reaction is based on the premise that every individual exhibits a personal degree of total risk aversion. Total risk can be defined as the product of business risk (i.e., the risks associated with particular business enterprises) and financial risk (i.e., the added risk associated with the debt financing of the enterprise). The individual focus is on total risk, and any reduction in one of its components will be offset by an increase in the other.

\section{The survey}

The survey was applied to 24 livestock farmers in Southland and 24 arable farmers in Central Canterbury during February 1990. A slightly modified survey instrument was also given to 32 Waikato dairy farmers in July 1990. It is important to emphasise that the selection of the farmer respondents was not made on a random basis, but rather was intended to provide a sample of farmers that conformed to predetermined and objectively assessed selection criteria. As a result, the findings of the survey and any conclusions drawn from their analysis are not expected to be representative of the entire population. The following discussion should be viewed with that limitation in mind.

The selection of farmers was made by experienced agriculturalists in each region in an attempt to cover all of the relevant combinations of three separate criteria. Fist, the farmers were divided according to the stage of the business life cycle with the categories of new entrants, developing farmers and mature or consolidating farmers. The second criterion was farmer ability with the four possible categories being well above average, above average, average and below average. Third. the group of respondents was separated with reference to their apparent attitudes towards farm risk. This dimension is obviously the most difficult to accurately identify on an ex ante basis due both to the problems of defining risk aversity and then subjectively assessing each of the farmers' attitudes towards risk. Nevertheless, an attempt has been made to describe each respondent as being either a risk seeker, risk neutral or risk averse, with the decision based mainly on the intensity of the farming system adopted and the level of debt funds used to finance the business.
Responses were sought relating to the farmers' perceptions of past and future business risks (classified as climatic, technological, managerial, and marketing) and financial risks. and to the strategies that they had followed in the past and believed that they would follow in the future to control those risk sources.

The results of the survey were analysed initially to obtain the mean responses for each question in each region. The responses were also used as input for multiple discriminant analysis, in an attempt to identify the differences between the regions.

\section{Results}

\section{Southland farmer characteristics}

The following characteristics appear to exemplify the attitudes and behaviour of Southland farmers:

* The survey finding of most consequence suggests that the nature of farm asset ownership remains of paramount importance to the Southland farmer, to the exclusion of virtually all other apparently beneficial alternatives. Freehold and individual land ownership appears to be the primary objective of the majority of farmers. and their acceptance of various strategies which are designed to ameliorate financial risk may be limited by this factor. All respondents consider the level of debt to be very important to decision making, and on average the existing level of debt was higher than that which is considered manageable. But if given the opportunity to replace debt with outside equity, either in return greater profitability or lower income variability. only a small number would do so. Further, one half of the Southland respondents would definitely not replace debt with outside equity even if they could repurchase the equity share at a price they considered fair, and only $2 \%$ of the surveyed farmers would consider this option if therepurchsseprice of the equity share was set at market levels. Thus, the opportunities for reducing financial risk afforded by alterations to the existing farm ownership structure appear to be restricted by farmer attitudes.

Approximately one half of the Southland respondents had either purchased land additional to their first farm, significantly diversified their enterprise mix or completed a land development programme during the past 20 years. However, when given the benefit of hindsight only about $50 \%$ of those who did diversify would do so again, and under half would now consider land 
development. Reasons given for the lack of enthusiasm over diversification include the desire for specialisation and simplification of manage ment, the limited number of viable options available, and workload considerations. That nearly $75 \%$ of those who purchased additional land would do the same thing again today may indicate that farm expansion is considered to be a better response to increasing risk levels than the other two alternatives.

* The only perceived dimatic risk was rainfall, but this was not strongly supported as a contributing risk factor. Strategies favoured in combatting climatic risk include shelter planting, hay storage, drainage and winterfeed crops, none of which were rated as being very important.

Technology based strategies aimed at controlling production risk found favour. For example, soil tests, performance based stock selection and management systems, and maintenance fertiliser were the common choices.

Managerially oriented strategies included asset insurance (strongly favoured), with moderate favour being expressed for enterprise intensification, off-farm investment, the use of information (pasture production, liveweights, cash flow monitoring), the use of farm advisors and discussion groups. and the use of cooperatives.

Marketing strategies (moderately supported) induded product specification standards, flexible selling dates, the use of cooperatives. and pooling mechanisms.

Overall, the survey results suggest that the attitude of Southland farmers towards potential risk reducing strategies is strongly influenced by their attitude to land ownership. The farmers indicate that the strategies which aremost likely to be accepted revolve around either improving or expanding their existing farm enterprise systems.

\section{Discriminant analysis results}

The second part of the research on which this paper is based was to observe the differences between farmers in the three different geographical regions. The objective was to observe the differences between the groups and was not to attempt to speculate on the reasons for the differences.

The study showed that farmers' perceptions of the sources of risk differed when grouped on a regional farming system basis. Group differences related not only to industry specific variables, but also to some widely held predictors of risk such as the debt ratio.
Southland farmers do differ in their perceptions of from their counterparts in both Canterbury and Waikato in the following ways:

* Southland farmers are more insistent that they have individual and freehold ownership of the farm assets. They also place more emphasis on other noneconomic, family based goals. They are therefore less likely to accept some potential risk reduaing strategies such as alternative asset ownership structures.

Southland farmers are less interested in diversifying their existing enterprisemix. This is due to the perceived lack of viable alternatives, or because they fed they lack the necessary expertise to succeed with any alternative enterprise.

\section{Conclusion}

Two major points can be derived from the analysis that was undertaken, and these points should be considered both by those responsible for agricultural policy development, and by those dealing with Southland fanners on an individual basis.

First, in addition to their very strong empathy for the ownership of land, Southland farmers value knowledge very highly. Their responses to perceived risks almost entirely revolve around mastering the latest technological advances. This strength is one worthy of focus by those especially responsible for extension programmes.

second, policy makers must be aware that different groups of farmers not only perceive there being different risks to be considered, but also offer different responses to those risks. The natural corollary to this finding is that policy orientation should be regionally, or farming system based if the desired response is to be achieved.

In summary, it appears that the best advice that can be given to Southland farmers (at least in terms of their own perceptions), is to expand their farming operations and to get better at what they are doing via the introduction of the latest technologies. These may be the only risk reduaing options that will be considered positively.

\section{REFERENCES}

Gabriel, S.C.; Baker, C.B. 1980. "Concepts of Business and Financial Risk" American Journal of Agricultural Economics

Newman, D.L.; Pittaway, S.F.; Saunders, L.S.; Gow, N.G. 1990. Risk management at the farm level (Projects $89 / 7$ and 89/8). Unpublishedreport for Ministry of Agriculture and Fisheries, Rural Policy Unit. 
Newman, D.L.; Pittaway, S.F.; Saunders, L.S.; Gow, N.G. 1990. The theory of agricultural risk management and the attitudes of farmers and financiers. In Management of risk in New Zealand farming". MAF Technology. 45-66.

Newman, D.L.; Saunders, L.S.; Pittaway, S.F.; Anderson. G.A. 1991. Multidiscriminant analysis of farmer risk responses. Proceedings of the New Zealand Branch of the Australian Agricultural Economics Society Sixteenth Annual Conference. Lincoln University.

Saunders.S.; Newman, D.L.; Pittaway, S.F.; Anderson, G.A. 1991. Farmers' perceptions of risk: naive or irrational? Proceedings of the New Zealand Branch of the Australian Agricultural Economics Society Sixteenth Annual Conference. Lincoln University. 